\title{
Independent Effects of Aldosterone and Potassium on Induction of Potassium Adaptation in Rat Kidney
}

\author{
Bruce Stanton, Luying Pan, Hans Deetjen, Victoria Guckian, and Gerhard Giebisch \\ Department of Physiology, Dartmouth Medical School, Hanover, New Hampshire 03756; \\ and Department of Physiology, Yale University School of Medicine, New Haven, Connecticut 06510
}

\begin{abstract}
We examined the independent effects of a high potassium diet and increased aldosterone levels on the development of renal potassium adaptation. This condition is defined by the increased ability of the kidneys to excrete an acute infusion of potassium. Rats were adrenalectomized (ADX) and received aldosterone at basal levels $(0.5 \mu \mathrm{g} / 100 \mathrm{~g} \cdot \mathrm{d})$ or at high levels $(2.0 \mu \mathrm{g} / 100 \mathrm{~g} \cdot \mathrm{d})$ for $10 \mathrm{~d}$. In each experimental group, animals received either a control diet or a high potassium diet. In ADX animals with basal aldosterone levels, a high potassium intake increased but did not completely restore the ability to excrete potassium and induced proliferation of the basolateral membrane of principal cells in the collecting tubule (i.e., morphologic adaptation). In contrast, increased aldosterone did not induce functional adaptation. Elevated aldosterone and dietary potassium intake were required to produce functional potassium adaptation indistinguishable from that in potassium-loaded, adrenal-intact animals.
\end{abstract}

\section{Introduction}

After a chronic increase in dietary potassium intake, a sequence of adaptive changes takes place in the kidneys that lead to the more effective and enhanced excretion of potassium after an acute potassium load (1-16). This response, called potassium adaptation, is associated with a sharp elevation of plasma aldosterone levels and with an increase in potassium secretion by the initial collecting, cortical collecting, and medullary collecting tubules $(1-3,11,12,17-21)$. A high potassium intake also stimulates $\mathrm{Na}, \mathrm{K}-\mathrm{ATPase}(3,4,11,13-15,22,23)$ and induces selective amplification of the basolateral membrane of principal cells in the cortical, and medullary collecting tubules $(1,10$, 12, 24).

The results of several investigations suggest that changes in potassium intake and in aldosterone levels contribute to the development of the functional, morphologic, and enzymatic changes that characterize potassium adaptation. For example, an increase in plasma aldosterone for $10 \mathrm{~d}$ in adrenalectomized rats ingesting a control diet increases the ability of the kidneys

Portions of this work have been published in abstract form (1986. Proceedings of the International Union of Physiological Sciences. Vol. 16. 86).

Address reprint requests to Dr. Stanton, Department of Physiology, Dartmouth Medical School, Hanover, NH 03756.

Received for publication 24 March 1986 and in revised form 4 August 1986.

J. Clin. Invest.

(c) The American Society for Clinical Investigation, Inc.

0021-9738/87/01/0198/09 \$1.00

Volume 79, January 1987, 198-206 to excrete an acute infusion of potassium (25) and induces amplification of the basolateral membrane of principal cells in the initial collecting tubule (26). A chronic high potassium intake also increases $\mathrm{Na}, \mathrm{K}$-ATPase in cortical collecting tubules of adrenalectomized adrenal hormone-deficient animals (13-15). Micropuncture $(12,27)$, microcatheterization (28), and microperfusion $(1-3,19-21,29-31)$ studies in vivo and in vitro have shown that aldosterone and a high potassium diet enhance potassium secretion by the initial collecting, cortical collecting, and medullary collecting tubule.

Despite the recognition that both a high potassium diet and an increase in aldosterone stimulate potassium secretion by the collecting tubule, the quantitative contribution of each of these factors in the expression of functional and morphologic potassium adaptation has not been fully resolved. The present study was conducted to examine the independent effects of a high potassium diet and elevated aldosterone on the development of functional and structural potassium adaptation.

We demonstrate that a high potassium intake alone induces functional potassium adaptation, but not to the extent observed in adrenal-intact animals in which both potassium intake and aldosterone levels are high. In addition, a high potassium intake induces significant amplification of the basolateral membrane of principal cells in the collecting tubule.

We observed that the effects of aldosterone on potassium excretion depend on the dietary potassium intake. When dietary intake of potassium was normal, an increase in aldosterone did not induce functional potassium adaptation. However, aldosterone was effective in stimulating renal potassium excretion when animals received a high potassium diet. Under these conditions aldosterone induced full development of functional and morphologic potassium adaptation. We conclude that renal potassium adaptation, similar to that observed in adrenal-intact control animals, requires an increase in dietary potassium intake accompanied by appropriately elevated plasma aldosterone levels.

\section{Methods}

Pretreatment of animals. Male Sprague-Dawley rats (Charles River Breedings Laboratories, Inc., Boston, MA), weighing 181-193 g, were divided into six groups (Table I). Animals were either sham-adrenalectomized and served as controls (groups 1 and 2) or were adrenalectomized (groups 3-6), under Nembutal anesthesia ( $35 \mathrm{mg} / \mathrm{kg}$ body wt) $10 \mathrm{~d}$ before renal function or ultrastructural studies were performed. At the time of adrenalectomy an osmotic minipump (model 2002 Alza Corp., Palo Alto, CA) was inserted subcutaneously in the neck of each animal and served to infuse aldosterone and dexamethasone as described below and in Table $\mathrm{I}$.

Group 1: control, control diet (Prolab rat diet, Agway, Syracuse, NY, potassium $1.5 \%$ and sodium $0.58 \%$ ).

Group 2: control, high $\mathrm{KCl}$ diet ( $10 \mathrm{~g} \mathrm{KCl}$ added/100 $\mathrm{g}$ food). 
Table I. Pretreatment of Animals

\begin{tabular}{|c|c|c|c|}
\hline Group & $\begin{array}{l}\text { Surgical } \\
\text { treatment }\end{array}$ & Hormone treatment & Diet \\
\hline & & $\mu g / 100 \mathrm{~g} \cdot d$ & \\
\hline 1. Control & None & None & Control \\
\hline 2. Control & None & None & $\mathrm{KCl}$ \\
\hline 3. ADX:basal Aldo & ADX & $\begin{array}{l}\text { Aldosterone } 0.5 \\
\text { Dexamethasone } 1.2\end{array}$ & Control \\
\hline 4. ADX:basal Aldo & ADX & $\begin{array}{l}\text { Aldosterone } 0.5 \\
\text { Dexamethasone } 1.2\end{array}$ & $\mathrm{KCl}$ \\
\hline 5. ADX:high Aldo & ADX & $\begin{array}{l}\text { Aldosterone } 2.0 \\
\text { Dexamethasone } 1.2\end{array}$ & Control \\
\hline 6. ADX:high Aldo & ADX & $\begin{array}{l}\text { Aldosterone } 2.0 \\
\text { Dexamethasone } 1.2\end{array}$ & $\mathrm{KCl}$ \\
\hline
\end{tabular}

Abbreviations: ADX, adrenalectomized; basal Aldo, basal aldosterone; high Aldo, high dose of aldosterone.

Group 3: adrenalectomy plus basal hormone replacement: aldosterone $(0.5 \mu \mathrm{g} / 100 \mathrm{~g}$ body $\mathrm{wt} \cdot \mathrm{d})$ and dexamethasone $(1.2 \mu \mathrm{g} / 100 \mathrm{~g}$ body $\mathrm{wt} \cdot \mathrm{d})$, control diet.

Group 4: adrenalectomy plus basal hormone replacement: aldosterone $(0.5 \mu \mathrm{g} / 100 \mathrm{~g}$ body wt $\cdot \mathrm{d})$ and dexamethasone $(1.2 \mu \mathrm{g} / 100 \mathrm{~g}$ body $\mathrm{wt} \cdot \mathrm{d})$ high $\mathrm{KCl}$ diet $(10 \mathrm{~g} \mathrm{KCl}$ added/100 $\mathrm{g}$ food).

Group 5: adrenalectomy plus high aldosterone replacement $(2.0 \mu \mathrm{g} /$ $100 \mathrm{~g}$ body $\mathrm{wt} \cdot \mathrm{d})$ and dexamethasone $(1.2 \mu \mathrm{g} / 100 \mathrm{~g}$ body $\mathrm{wt} \cdot \mathrm{d})$, control diet.

Group 6: adrenalectomy plus high aldosterone replacement (2.0 $\mu \mathrm{g} /$ $100 \mathrm{~g}$ body $\mathrm{wt} \cdot \mathrm{d})$ and dexamethasone $(1.2 \mu \mathrm{g} / 100 \mathrm{~g}$ body $\mathrm{wt} \cdot \mathrm{d})$, high $\mathrm{KCl}$ diet $(10 \mathrm{~g} \mathrm{KCl}$ added/100 $\mathrm{g}$ food).

We have shown previously that the aldosterone infusion rate of 0.5 $\mu \mathrm{g} / 100 \mathrm{~g} \cdot \mathrm{d}$ restored plasma levels of aldosterone to control values and that $2.0 \mu \mathrm{g} / 100 \mathrm{~g} \cdot \mathrm{d}$ increased hormone levels to those measured in adrenal-intact rats on a high potassium diet (2). The dose of dexamethasone given to the adrenalectomized rats was the lowest one that increased glomerular filtration rate and plasma levels of insulin and glucose to those measured in control rats (2).

All animals were pair-fed; food intake varied between 15 and $18 \mathrm{~g}$ per day. Animals on the control diet ingested 5.7-6.8 meq of potassium/ $\mathrm{d}$ and animals on the high potassium diet ingested $25.7-30.8 \mathrm{meq}$ of potassium/d. Distilled water was available ad libitum.

Experimental protocol for clearance experiments. Rats were anesthetized with Inactin (Byk Gluden, Konstanz, Germany, $100 \mathrm{mg} / \mathrm{kg}$ body wt i.p.) and a tracheostomy tube was inserted to insure adequate ventilation. Throughout the study body temperature was maintained at 37$37.5^{\circ} \mathrm{C}$. The left carotid artery and left external jugular vein were cannulated for the withdrawal of blood samples and infusion of all test substances, respectively. Bladder catheterization was performed to allow complete collection of urine from both kidneys.

After surgery, all rats received a 2-ml bolus of Ringer's solution (in millimolar: $\mathrm{NaCl} 115, \mathrm{NaHCO}_{3} 25, \mathrm{KCl} 5$ ). This was followed by a maintenance infusion of Ringer's solution containing 3\% polyvinylpyrolidine (PVP) ${ }^{1}$ given at a rate of $4.7 \mathrm{ml} / \mathrm{h}$ (Fig. 1). PVP was given because it maintains glomerular filtration rate in adrenalectomized animals given $\mathrm{KCl}$ intravenously (25). After initiation of the maintenance infusion, a bolus of tritiated inulin $(25 \mu \mathrm{Ci}$, radiochemical purity $98.5 \%$, New England Nuclear, Boston, MA) was given, and inulin was added to the

1. Abbreviation used in this paper: PVP, polyvinylpyrolidine.
Ringer's solution to provide $25 \mu \mathrm{Ci} / \mathrm{h}$. After a 45 -min equilibration period, a baseline control urine collection was obtained. Thereafter, $\mathrm{KCl}$ was infused at a rate of $7 \mu \mathrm{mol} / \mathrm{min}$ by substituting the Ringer's solution for one containing $90 \mathrm{mM} \mathrm{KCl}, 30 \mathrm{mM} \mathrm{NaCl}, 25 \mathrm{NaHCO}_{3}$, and 3\% PVP. After a 30-min equilibration period, two 30-min experimental urine collections were obtained (Fig. 1). Blood samples were obtained at the beginning and end of each period.

Analytical determinations. Plasma and urine sodium and potassium concentrations were measured with a flame photometer using an internal lithium standard (Instrumentation Laboratory, Inc., Lexington, MA). Inulin concentrations in plasma and urine were measured by standard techniques (25). Plasma aldosterone concentration was measured by radioimmunoassay (Diagnostic Products Corp., Los Angeles, CA). Glomerular filtration rate and urinary excretion rates of sodium and potassium were calculated by standard formula (25).

Ultrastructural studies. To examine the effects of a high potassium diet on the ultrastructure of the initial collecting tubule, the kidneys from four groups of animals were prepared for electron microscopy. Rats in groups 3 and 4, adrenalectomized animals, were studied to examine the effects of a high $\mathrm{KCl}$ diet when aldosterone levels were constant. Groups 1 and 2, sham-adrenalectomized animals, were studied to examine the combined effects of an increase in aldosterone and dietary $\mathrm{KCl}$ intake on cell structure. In a previous study we examined the effects of a high potassium diet on cell structure for 4-6 wk (1).

Kidneys were prepared for electron microscopy as described previously $(1,26)$. Two to four initial collecting tubules, from each kidney, that were in contact with the renal capsule were selected for study. For each animal 13-18 cells, which were cut in cross section and had intact basement membranes and visible tight junctions, were photographed with an electron microscope (model 10B; Carl Zeiss, Inc., Thornwood, NY) and enlarged during printing to a magnification of $\times 10,000$. To eliminate possible observer bias, we coded all sections and micrographs. The code was broken only after all measurements had been made. The results of each animal represent a single observation. The following parameters were measured in each cell by methods described in detail previously $(1,26)$ : (a) surface density, which is the ratio of membrane area to cell volume $\left(\mathrm{S}_{\mathrm{v}}\right) ;(b)$ boundary length, which is the length of membrane $(B)$; and $(c)$ cell area (A).

Statistics. When appropriate, statistical differences between group means were compared using Student's $t$ test. Otherwise, preliminary inspection of the data was done by a one-way analysis of variance. If there was a significant value of $F$ at $P<0.05$, the Least Significant Difference test was used to identify statistical significance between means $(25,26)$. All data are expressed as the mean \pm standard error.

\section{Results}

Renal function: Ringer's period. Table II summarizes plasma and urine electrolyte data, as well as glomerular filtration rates during the Ringer's solution infusion period. The most striking observation is that potassium excretion in animals on the control diet, expressed as either total or fractional excretion rates, was similar in all experimental groups regardless of hormone levels (groups 1, 3, and 5). Thus, adrenalectomized animals given appropriate replacement doses of adrenal corticosteroids excreted

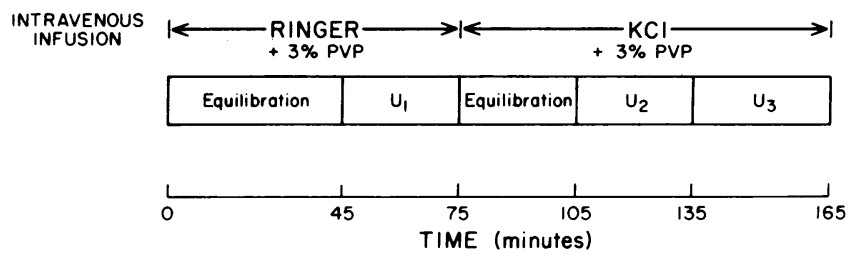

Figure 1. Protocol for clearance experiments. Details are presented in the text. 
Table II. Summary of Clearance Experiments during Infusion of Ringer's Solution

\begin{tabular}{|c|c|c|c|c|c|c|c|c|c|c|}
\hline Group & Diet & $(n)$ & GFR & $\mathbf{v}$ & $\mathrm{U}_{\mathrm{Na}} \mathrm{V}$ & $\mathrm{FE}_{\mathrm{Ne}_{\mathrm{e}}}$ & $\mathbf{U}_{\mathbf{k}} \mathbf{V}$ & $\mathrm{FE}_{\mathbf{K}}$ & $\mathbf{P}_{\mathbf{K}}$ & $\mathbf{P}_{\mathbf{N}_{\omega}}$ \\
\hline & & & $\mathrm{ml} / \mathrm{min}$ & $\mu l / m i n$ & $\mu e q / \min$ & $\%$ & $\mu e q / \min$ & $\%$ & meq/liter & meq/liter \\
\hline \multirow[t]{2}{*}{ 1. Control } & C & 7 & 2.99 & 38.71 & 1.24 & 0.27 & 2.39 & 17.42 & 4.37 & 146.71 \\
\hline & & & \pm 0.25 & \pm 15.26 & \pm 0.37 & \pm 0.09 & \pm 0.33 & \pm 1.74 & \pm 0.07 & \pm 1.21 \\
\hline \multirow{2}{*}{ 2. Control } & $\mathrm{KCl}$ & 10 & 2.48 & 57.20 & 1.97 & 0.65 & 4.83 & 54.09 & 3.95 & 146.90 \\
\hline & & & \pm 0.22 & \pm 10.98 & \pm 0.51 & \pm 0.20 & \pm 0.48 & \pm 7.52 & \pm 0.15 & \pm 1.12 \\
\hline \multirow[t]{2}{*}{ 3. ADX:basal Aldo } & C & 11 & 2.72 & 23.63 & 2.79 & 0.72 & 1.42 & 15.08 & 3.99 & 147.23 \\
\hline & & & \pm 0.16 & \pm 6.08 & \pm 0.97 & \pm 0.27 & \pm 0.19 & \pm 1.89 & \pm 0.11 & \pm 1.14 \\
\hline \multirow[t]{2}{*}{ 4. ADX:basal Aldo } & $\mathrm{KCl}$ & 12 & 2.67 & 30.38 & 2.41 & 0.60 & 4.44 & 41.39 & 4.43 & 145.54 \\
\hline & & & \pm 0.20 & \pm 5.61 & \pm 0.77 & \pm 0.18 & \pm 0.85 & \pm 9.22 & \pm 0.23 & \pm 1.23 \\
\hline \multirow[t]{2}{*}{ 5. ADX:high Aldo } & $\mathrm{C}$ & 5 & 2.44 & 30.74 & 3.48 & 0.95 & 1.89 & 24.69 & 2.90 & 145.60 \\
\hline & & & \pm 0.18 & \pm 5.64 & \pm 0.70 & \pm 0.17 & \pm 0.40 & \pm 2.33 & \pm 0.13 & \pm 0.68 \\
\hline \multirow[t]{2}{*}{ 6. ADX:high Aldo } & $\mathrm{KCl}$ & 8 & 2.40 & 25.64 & 0.50 & 0.15 & 6.14 & 64.40 & 4.33 & 146.38 \\
\hline & & & \pm 0.29 & \pm 3.76 & \pm 0.19 & \pm 0.06 & \pm 0.84 & \pm 9.11 & \pm 0.39 & \pm 0.91 \\
\hline \multirow[t]{5}{*}{ Statistical comparisons } & & 1 vs. 2 & NS & NS & NS & NS & $P<0.05$ & $P<0.01$ & NS & NS \\
\hline & & 3 vs. 4 & NS & NS & NS & NS & $P<0.01$ & $P<0.01$ & NS & NS \\
\hline & & 5 vs. 6 & NS & NS & $P<0.01$ & $P<0.05$ & $P<0.01$ & $P<0.01$ & $P<0.01$ & NS \\
\hline & & 3 vs. 5 & NS & NS & NS & NS & NS & $P<0.05$ & NS & NS \\
\hline & & 4 vs. 6 & NS & NS & $P<0.01$ & $P<0.05$ & $P<0.05$ & $P<0.01$ & NS & NS \\
\hline
\end{tabular}

Abbreviations: ADX, adrenalectomized; $n$ equals the number of animals per group; $V$, urine flow rate; $U_{\mathrm{Na}} V$, urine sodium excretion; $U_{\mathrm{K}} \mathrm{V}$, urine potassium excretion; $\mathrm{FE}_{\mathrm{Na}}$, fractional excretion of sodium; $\mathrm{FE}_{\mathbf{K}}$, fractional excretion of potassium; $\mathbf{P}_{\mathbf{K}}$, plasma potassium concentration; $\mathbf{P}_{\mathrm{Na}}$, plasma sodium concentration. Statistical differences among group means determined by one-way analysis of variance and the Least Significant Difference test. Data expressed as mean \pm SE.

potassium at a rate similar to adrenal-intact controls. Significant changes in glomerular filtration rate, in rates of water and sodium excretion, or in plasma sodium and potassium levels were not observed.

In animals with elevated aldosterone levels on the control diet potassium excretion was also similar to that observed in the two groups with basal aldosterone levels. However, plasma potassium concentration was reduced significantly in the high aldosterone group. This observation confirms the finding of Young and Paulsen (32) that potassium excretion may be maintained at normal levels in spite of a significant reduction in plasma potassium concentration provided mineralocorticoid levels are appropriately elevated. The observed reduction in plasma potassium concentration is most likely due to an aldosterone-induced shift of potassium into extrarenal tissues (32-34). Some potassium depletion may also have occurred during the 10-d pretreatment period with the high aldosterone infusion (9).

Potassium excretion was significantly enhanced in all groups of animals given the high potassium diet (groups 2, 4, and 6) compared with those on the control diet (groups 1,3 , and 5). We also observed that in all animals on the high potassium diet, renal potassium excretion was similar despite significant differences in steroid hormone levels.

Compared with animals on the control diet, the high potassium diet (groups 2, 4, and 6) had no significant effect on glomerular filtration rate, urine flow rate, or sodium excretion. Thus, differences in these factors cannot account for the increase in potassium excretion in the animals on the high potassium diet. Moreover, alterations in plasma potassium also cannot account for the higher rates of potassium excretion in the animals receiving a high potassium diet because plasma potassium concentration, which regulates potassium excretion (35), was either similar to or even less than in animals on the control diet.

Renal function: $\mathrm{KCl}$ period. Results of the effects of a high potassium diet and aldosterone on the ability of the kidneys to excrete an acute infusion of $\mathrm{KCl}$ load, are presented in Table III and Fig. 2.

In adrenal-intact control animals, a high potassium diet significantly increased plasma aldosterone as well as total and fractional potassium excretion after an acute infusion of $\mathrm{KCl}$ (groups 1 vs. 2 , Fig. 2). These data confirm previous observations (2, 5$9,11,17,18,27,28)$ and extend them by demonstrating that potassium adaptation is induced after $10 \mathrm{~d}$.

Administration of a high potassium diet, without an increase in aldosterone, also enhanced the ability of the kidneys to excrete potassium (groups 3 vs. 4, Fig. 2). However, adrenalectomized animals receiving basal aldosterone infusion on the high potassium diet excreted less potassium, $7.41 \mu \mathrm{eq} / \mathrm{min}$, than the adrenal-intact control group receiving the same high potassium diet, $9.05 \mu \mathrm{eq} / \mathrm{min}$.

An increase in dietary potassium intake alone in rats given high aldosterone also increased the ability to excrete an acute $\mathrm{KCl}$ infusion (groups 5 vs. 6, Table III and Fig. 2). However, an increase in both aldosterone and dietary potassium intake in adrenalectomized rats was required to increase potassium excretion, in response to the acute $\mathrm{KCl}$ infusion, to a rate similar to that observed in adrenal-intact controls on the high potassium diet. Therefore, a high potassium diet and an increase in aldo- 
Table III. Summary of Clearance Experiments during KCl Infusion

\begin{tabular}{|c|c|c|c|c|c|c|c|c|c|c|}
\hline Group & Diet & $(n)$ & GFR & $\mathbf{v}$ & $\mathrm{U}_{\mathrm{N}} \mathrm{V}$ & $\mathrm{FE}_{\mathrm{N}_{\boldsymbol{\omega}}}$ & $\mathrm{U}_{\mathbf{k}} \mathbf{V}$ & $\mathrm{FE}_{\mathbf{k}}$ & $\mathbf{P}_{\mathbf{k}}$ & $\mathbf{P}_{\mathrm{Ne}}$ \\
\hline & & & $\mathrm{ml} / \mathrm{min}$ & $\mu l / m i n$ & $\mu e q / \min$ & $\%$ & $\mu e q / \min$ & $\%$ & meq/liter & meq/liter \\
\hline \multirow[t]{2}{*}{ 1. Control } & $\mathrm{C}$ & 7 & 2.58 & 93.94 & 6.84 & 2.10 & 7.83 & 63.04 & 5.10 & 147.50 \\
\hline & & & \pm 0.14 & \pm 13.90 & \pm 1.43 & \pm 0.58 & \pm 0.22 & \pm 3.03 & \pm 0.34 & \pm 1.97 \\
\hline \multirow[t]{2}{*}{ 2. Control } & $\mathrm{KCl}$ & 10 & 2.30 & 119.54 & 8.21 & 2.56 & 9.05 & 107.14 & 3.88 & 147.32 \\
\hline & & & \pm 0.15 & \pm 7.79 & \pm 1.14 & \pm 0.38 & \pm 0.25 & \pm 8.68 & \pm 0.11 & \pm 0.60 \\
\hline \multirow[t]{2}{*}{ 3. ADX:basal Aldo } & $\mathrm{C}$ & 11 & 2.51 & 96.40 & 7.62 & 2.31 & 5.94 & 51.98 & 4.90 & 146.07 \\
\hline & & & \pm 0.22 & \pm 6.40 & \pm 1.16 & \pm 0.32 & \pm 0.42 & \pm 3.45 & \pm 0.14 & \pm 0.64 \\
\hline \multirow[t]{2}{*}{ 4. ADX:basal Aldo } & $\mathrm{KCl}$ & 12 & 2.29 & 100.91 & 7.54 & 2.33 & 7.41 & 70.20 & 5.19 & 142.81 \\
\hline & & & \pm 0.17 & \pm 8.03 & \pm 1.15 & \pm 0.30 & \pm 0.42 & \pm 5.56 & \pm 0.13 & \pm 0.89 \\
\hline \multirow[t]{2}{*}{ 5. ADX:high Aldo } & $\mathrm{C}$ & 5 & 2.26 & 86.09 & 8.77 & 2.74 & 4.04 & 48.96 & 3.78 & 144.70 \\
\hline & & & \pm 0.12 & \pm 6.61 & \pm 0.73 & \pm 0.19 & \pm 0.24 & \pm 3.89 & \pm 0.14 & \pm 1.25 \\
\hline \multirow[t]{2}{*}{ 6. ADX:high Aldo } & $\mathrm{KCl}$ & 8 & 2.10 & 63.05 & 1.17 & 0.38 & 8.40 & 96.85 & 4.47 & 146.86 \\
\hline & & & \pm 0.17 & \pm 9.00 & \pm 0.35 & \pm 0.11 & \pm 1.06 & \pm 4.86 & \pm 0.32 & \pm 0.54 \\
\hline \multirow[t]{5}{*}{ Statistical comparisons } & & 1 vs. 2 & NS & NS & NS & NS & $P<0.05$ & $P<0.01$ & $P<0.01$ & NS \\
\hline & & 3 vs. 4 & NS & NS & NS & NS & $P<0.05$ & $P<0.05$ & NS & $P<0.01$ \\
\hline & & 5 vs. 6 & NS & NS & $P<0.01$ & $P<0.01$ & $P<0.05$ & $P<0.01$ & NS & $P<0.05$ \\
\hline & & 3 vs. 5 & NS & NS & NS & NS & $P<0.05$ & NS & $P<0.01$ & NS \\
\hline & & 4 vs. 6 & NS & $P<0.01$ & $P<0.01$ & $P<0.01$ & NS & $P<0.01$ & NS & $P<0.05$ \\
\hline
\end{tabular}

Abbreviations same as in Table II. Data expressed as mean \pm SE.

sterone are required for the full expression of functional renal potassium adaptation.

The independent effects of an increase in aldosterone on the development of renal functional potassium adaptation are presented in Table III and in Fig. 3. In animals on the control diet, a fivefold increase in plasma aldosterone did not augment the ability of the kidneys to excrete an acute infusion of $\mathrm{KCl}$ (groups 3 vs. 5, Fig. 3). Indeed, potassium excretion actually decreased in animals receiving high aldosterone; however, fractional excretion was not affected by an increase in aldosterone. It is noteworthy that the lack of an effect of aldosterone was accompanied by a significant decrease in plasma potassium concentration, from $4.90 \mathrm{meq} / \mathrm{liter}$ in adrenalectomized animals receiving the basal dose of aldosterone to $3.78 \mathrm{meq} / \mathrm{liter}$ in adrenalectomized animals on the high aldosterone infusion (Table III).

In contrast to the effects of increased aldosterone in animals on a control diet, an increase in aldosterone in animals ingesting the high potassium diet augmented fractional potassium excretion from $70.2 \%$ to $96.85 \%$. This last value was not significantly different from $107.14 \%$ which was the value for potassium excretion in control animals on the high potassium diet (Table III and Fig. 3, groups 2 vs. 6). Absolute excretion tended to increase as aldosterone was elevated in animals on the high potassium diet, however, the difference did not achieve statistical significance (Table III). When aldosterone increased in animals on a high potassium diet, plasma potassium did not change significantly. This observation may explain why aldosterone increases potassium excretion only in animals on the high potassium diet. Our data also show that a high potassium diet and high aldosterone levels are both required for the development of potassium adaptation equivalent to that produced by a similar high potassium diet in adrenal-intact animals (groups 2 vs. 6, Fig. 2).
Additional clearance data, obtained during the acute infusion of $\mathrm{KCl}$, are also presented in Table III. None of the factors known to affect the rate of urinary potassium excretion, such as glomerular filtration rate, urine flow rate, sodium excretion, and plasma potassium concentration, changed in a direction that could account for the increased excretion of potassium. Thus, changes in these factors cannot account for the development of renal potassium adaptation.

Ultrastructural studies. In adrenal-intact animals, the high potassium diet increased the length of the basolateral membrane of principal cells (groups 1 and 2, Table IV). Basolateral membrane length increased by $98.0 \%$. Because cell area increased significantly, surface density of the basolateral membrane only rose by $20.2 \%$, from $2.67 \pm 0.13$ to $3.21 \pm 0.14 \mu \mathrm{m}^{2} / \mu \mathrm{m}^{3}$. As shown previously in adrenal-intact animals, a high potassium diet selectively increased the length of the basolateral membrane of principal cells in the initial collecting tubule (1). The present study confirms this effect of dietary potassium and demonstrates that the proliferation is present after $10 \mathrm{~d}$ and can be induced by a smaller increase in potassium intake. Because of differences in the duration of the experiments and the content of the high potassium diets between our previous study and the present one, ${ }^{2}$ a quantitative comparison of the two studies is not appropriate.

2. Dietary potassium intake increased approximately fivefold in the present study for a 10-d period whereas it increased some 16-fold for 4-6 wk in our previous study (1). We reduced the potassium content of the high potassium diet in the present study because adrenalectomized animals with the basal aldosterone treatment did not survive a 16-fold increase in potassium intake. This observation also confirms the importance of an increase in aldosterone in the development of renal potassium adaptation when dietary potassium intake is increased. 

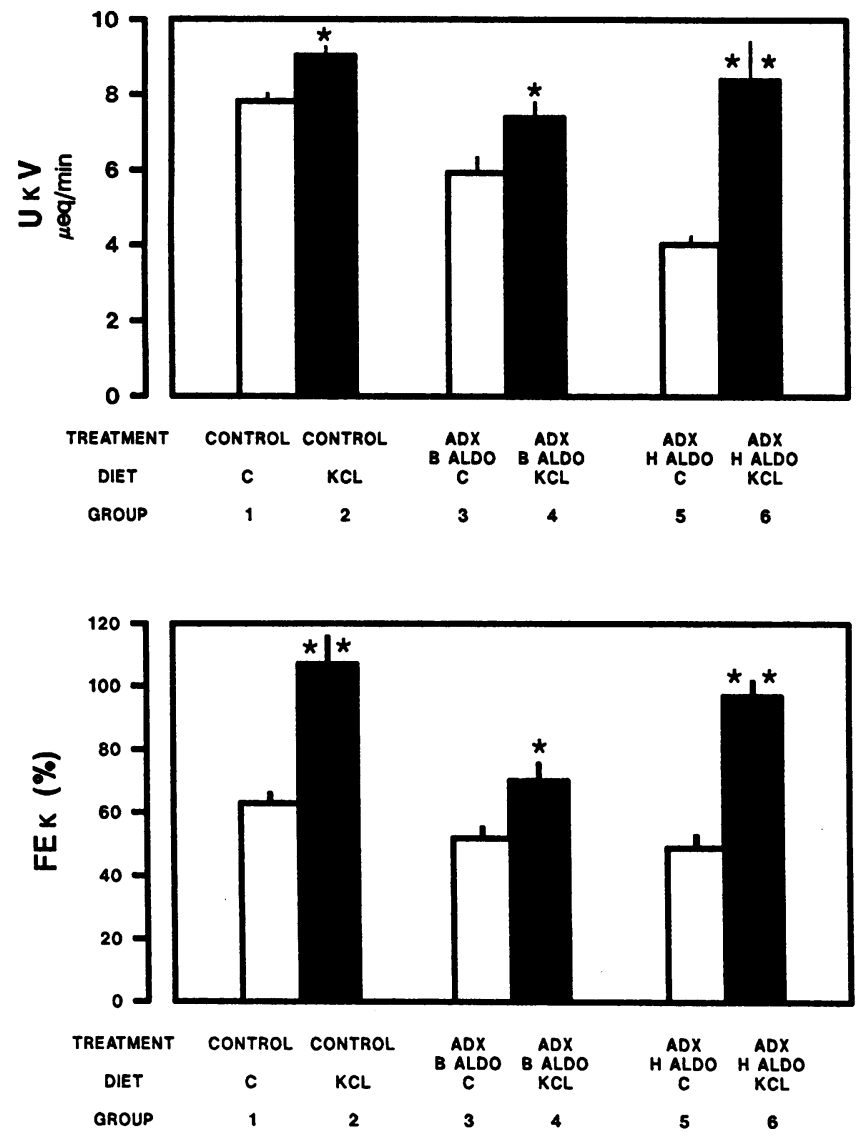

Figure 2. Effects of an increase in dietary potassium intake on potassium excretion during acute $\mathrm{KCl}$ loading. Abbreviations: $U_{\mathbf{K}} \mathrm{V}$, total excretion; $\mathrm{FE}_{\mathrm{K}}$, fractional excretion; $\mathrm{C}$, control diet; $\mathrm{KCl}$, high potassium diet; B ALDO, basal aldosterone; H ALDO, high dose of aldosterone. (Empty bar) control diet; (solid bar) high $\mathrm{K}$ diet. Asterisks indicate statistical significance where ${ }^{*} P<0.05$ and ${ }^{* *} P<0.01$. Data are expressed as mean $\pm \mathrm{SE}$.

The effects of an independent increase in dietary potassium intake on the structure of principal cells in initial collecting tubules are presented in Table IV and Fig. 4. Qualitatively, the most striking observation was that a high potassium intake, without an increase in plasma aldosterone levels, led to a significant increase in the length of the basolateral membrane of principal cells. This observation was confirmed by our quantitative morphometric analysis (Table IV). Basolateral membrane length increased by $56.0 \%$ after $10 \mathrm{~d}$ of a high potassium diet. Because cell area also increased significantly, from $69.0 \pm 5.3$ to $87.3 \pm 7.9 \mu \mathrm{m}^{2}$ per cell, the surface density of the basolateral membrane, which is the ratio of membrane area divided by cell volume, increased by only $18.4 \%$ from $2.82 \pm 0.15$ to $3.39 \pm 0.18$ $\mu \mathrm{m}^{2} / \mu \mathrm{m}^{3}$. This effect of potassium was limited to the basolateral membrane; neither luminal membrane length nor surface density increased significantly.

We have shown previously that administration of aldosterone at a rate of $2.0 \mu \mathrm{g} / 100 \mathrm{~g}$ body $\mathrm{wt} \cdot \mathrm{d}$ in adrenalectomized rats maintained on a constant potassium intake, increased the length of the basolateral membrane of principal cells (26). Treatment for $10 \mathrm{~d}$ with this dose of aldosterone increased the length of the basolateral membrane of principal cells from $121.4 \pm 7.4$ to $236.1 \pm 26.6 \mu \mathrm{m}$ per cell $(P<0.01)$ and increased the surface
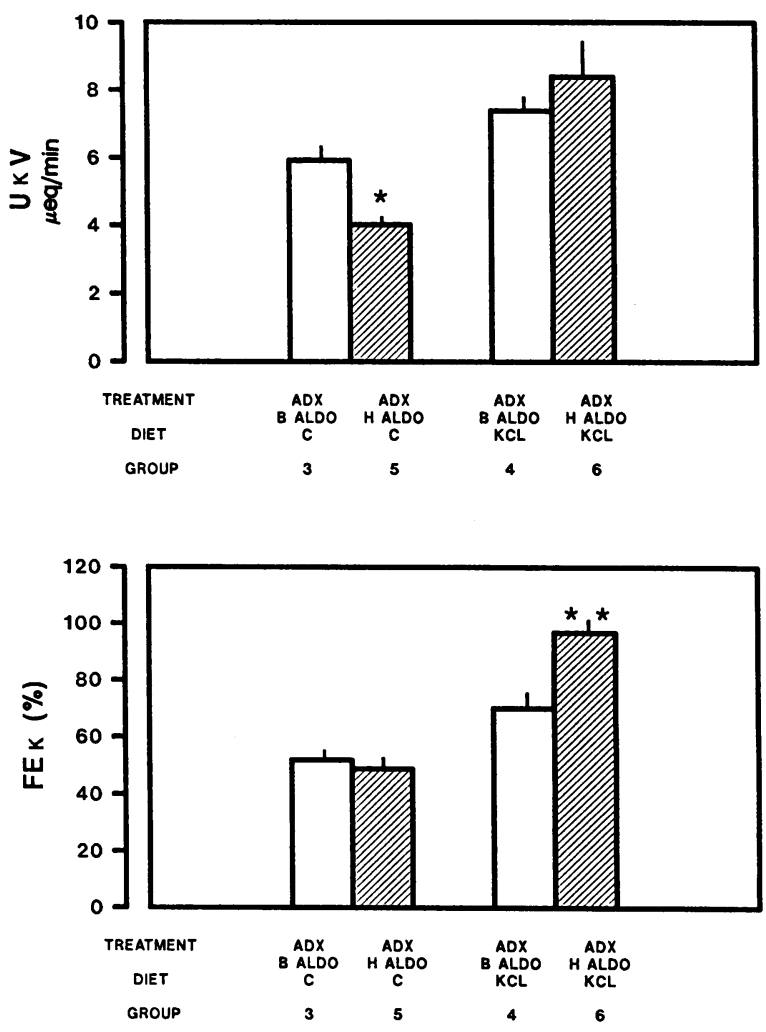

Figure 3. Effects of an increase in aldosterone levels on potassium excretion during acute $\mathrm{KCl}$ infusion. Abbreviations same as Fig. 2. (Empty bar) basal aldosterone; (hatched bar) high aldosterone.

density from $3.31 \pm 0.30$ to $3.87 \pm 0.13 \mu \mathrm{m}^{2} / \mu \mathrm{m}^{3}(P<0.05)$. Thus, aldosterone and a high potassium diet are capable of independently inducing proliferation of the basolateral membrane of principal cells.

\section{Discussion}

Many studies have shown in adrenal-intact animals that chronic ingestion of a high potassium diet induces a state of potassium adaptation, characterized by an increased ability to excrete an acute infusion of $\mathrm{KCl}(1-16)$ as well as by proliferation of the basolateral membrane of principal cells in the initial collecting and medullary collecting tubule $(1,10,24)$. In such animals the high potassium diet elicits a significant, approximate fourfold increase in plasma aldosterone levels $(1,2,12)$. Thus, it is not possible to evaluate the independent contribution of the increase in plasma aldosterone vs. a high potassium intake on the development of renal potassium adaptation. The present experiments were designed to permit such an analysis.

The main finding of our study is that an increase in dietary potassium intake, without a change in plasma aldosterone levels, induces significant but not complete restoration of renal functional potassium adaptation. A high potassium diet also leads to renal morphologic adaptation, defined as an increase in the length of the basolateral membrane of principal cells in the initial collecting tubule. We also observe that an increase in aldosterone, unaccompanied by a high potassium intake, does not enhance the ability of the kidneys to excrete an acute potassium load. This should not be taken to mean that aldosterone plays no role 

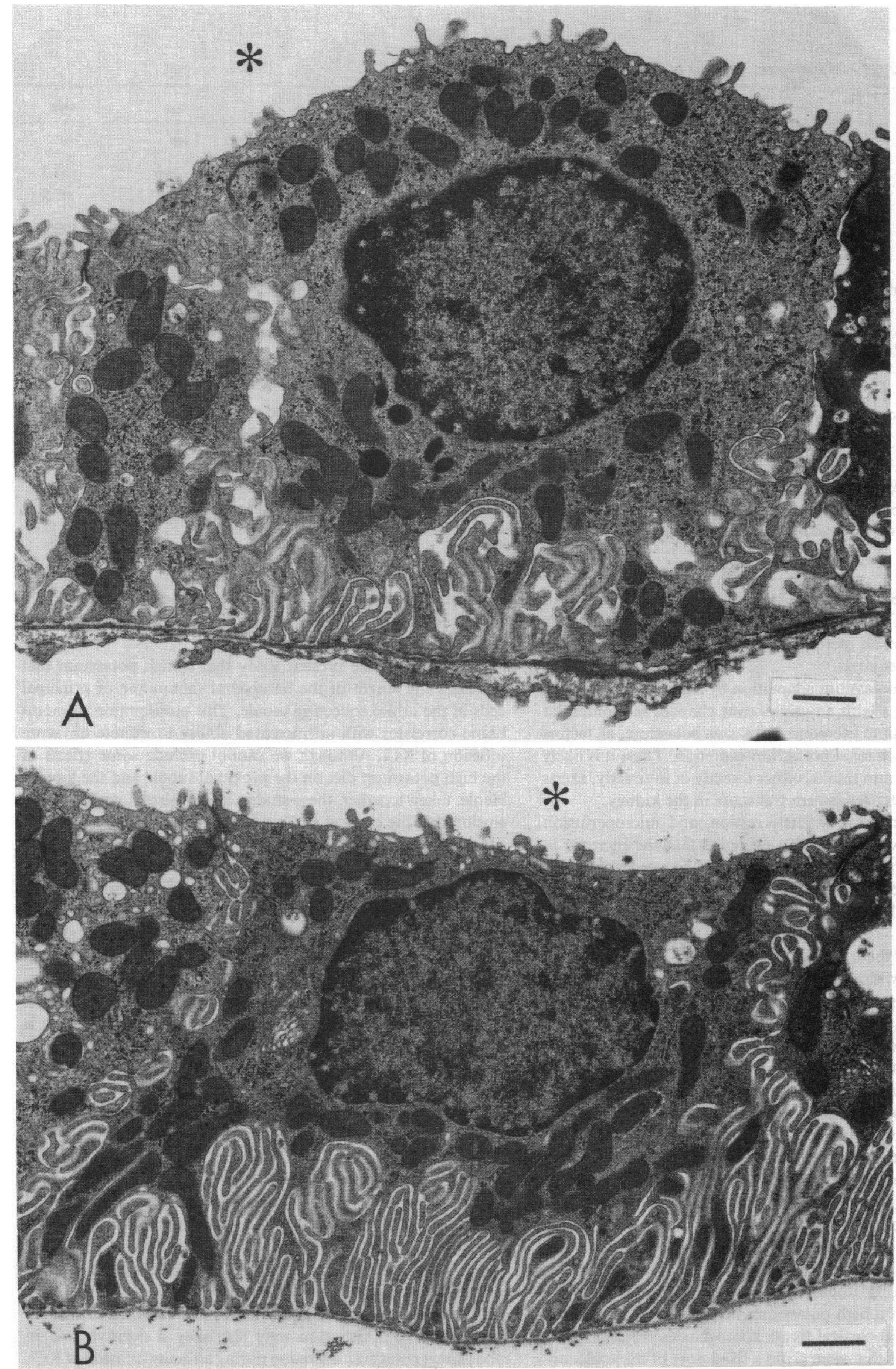

Figure 4. Electron micrographs of principal cells from the initial collecting tubule. (A) Adrenalectomized rats with basal hormone levels (group 3) on a control diet and $(B)$ adrenalectomized rats with basal hormone levels on a high potassium diet for $10 \mathrm{~d}$ (group 4). Bars equal $1 \mu \mathrm{m}$. Asterisks mark tubule lumen. 
Table IV. Summary of Morphometric Analysis of Principal Cells

\begin{tabular}{|c|c|c|c|c|c|c|c|}
\hline Group & Diet & $(n)$ & SvBLM & SvLM & $\mathbf{B}_{\mathrm{BLM}}$ & $\mathbf{B}_{\mathbf{L M}}$ & Area \\
\hline & & & $\mu m^{2} / \mu m^{3}$ & $\mu m^{2} / \mu m^{3}$ & $\mu m$ & $\mu m$ & $\mu m^{2}$ \\
\hline \multirow[t]{2}{*}{ 1. Control } & C & 5 & 2.67 & 0.44 & 131.5 & 20.6 & 63.3 \\
\hline & & & \pm 0.13 & \pm 0.06 & \pm 14.2 & \pm 1.2 & \pm 8.5 \\
\hline \multirow[t]{2}{*}{ 2. Control } & $\mathrm{KCl}$ & 8 & 3.21 & 0.28 & 260.4 & 21.8 & 102.6 \\
\hline & & & \pm 0.14 & \pm 0.04 & \pm 23.0 & \pm 1.4 & \pm 6.9 \\
\hline \multirow[t]{2}{*}{ 3. ADX:basal Aldo } & C & 6 & 2.82 & 0.37 & 150.3 & 19.8 & 69.0 \\
\hline & & & \pm 0.15 & \pm 0.03 & \pm 12.2 & \pm 1.4 & \pm 5.3 \\
\hline \multirow[t]{2}{*}{ 4. ADX:basal Aldo } & $\mathrm{KCl}$ & 8 & 3.39 & 0.36 & 234.5 & 23.6 & 87.3 \\
\hline & & & \pm 0.18 & \pm 0.04 & \pm 27.6 & \pm 3.5 & \pm 7.9 \\
\hline \multirow[t]{2}{*}{ Statistical comparisons } & & 1 vs. 2 & $P<0.01$ & $P<0.05$ & $P<0.01$ & NS & $P<0.01$ \\
\hline & & 3 vs. 4 & $P<0.01$ & NS & $P<0.01$ & NS & $P<0.01$ \\
\hline
\end{tabular}

Abbreviations: ADX, adrenalectomized; $n$ equals number of animals per group; $\mathrm{S}_{\mathrm{v}}$, surface density (membrane area/cell volume); B, boundary length (length of membrane); area, cell area; BLM, basolateral membrane; LM, luminal membrane. Statistical differences among group means determined by one-way analysis of variance and the Least Significant Difference test. Data expressed as mean $\pm \mathrm{SE}$.

in the development of renal potassium adaptation because our studies show that, for the development of the full renal functional adaptive response, an increase in potassium intake and plasma aldosterone are required.

Induction of potassium adaptation by a high potassium diet was not associated with any significant changes in glomerular filtration rate, sodium excretion, or plasma potassium, all factors known to influence renal potassium excretion. Thus, it is likely that a high potassium intake, either directly or indirectly, exerts an effect on tubular potassium transport in the kidney.

Micropuncture, microcatheterization, and microperfusion studies have provided extensive evidence that the increase in urinary potassium excretion in potassium-adapted animals is the result of increased secretion of potassium by the late distal tubule (initial collecting tubule) and the cortical and medullary collecting duct $(1-3,12,17-21,27,28)$. The increase in potassium secretion by these segments in potassium-adapted animals is also associated with proliferation of the basolateral membrane of principal cells and with an increase in the activity of $\mathrm{Na}, \mathrm{K}$-ATPase $(1,3,4,10-13,15,24)$.

Several lines of evidence suggest that an independent increase in dietary potassium intake alone, without a rise in plasma aldosterone, also leads to enhanced potassium secretion by distal nephron segments and thus may account for the increased ability of the kidney to excrete an acute $\mathrm{KCl}$ load. First, Wingo et al. (29) reported that an increase in the potassium content of the diet stimulated potassium secretion in isolated and perfused cortical collecting tubules from adrenalectomized rabbits. Electrophysiological observations in the isolated perfused cortical collecting tubule of the adrenalectomized rabbit also confirm that a high potassium intake stimulates potassium secretion by the cortical collecting tubule (30). Second, Silva and co-workers (13) observed that a high potassium diet increased the activity of Na,K-ATPase in cortical tissue homogenates from adrenalectomized animals that were given a fixed dose of mineralocorticoids. More recently, Garg and Narang (14) and Chekal et al. (15) localized this effect of a high potassium diet to the cortical collecting tubule. Thus, a high potassium intake either directly, or through a secondary and as yet undefined mechanism, enhances the activity of the sodium-potassium pump which promotes potassium secretion.

We show in the present study that a high potassium diet increases the length of the basolateral membrane of principal cells in the initial collecting tubule. This proliferation of membrane correlates with an increased ability to excrete an acute infusion of $\mathrm{KCl}$. Although we cannot exclude some effects of the high potassium diet on the proximal tubule and the loop of Henle, taken together, these studies are consistent with the conclusion that the cortical and medullary collecting ducts are key sites where an increase in dietary potassium intake stimulates functional and structural renal potassium adaptation.

In contrast to the stimulatory effect of potassium on the ability of the kidneys to excrete an exogenous potassium load, an independent increase in aldosterone, when dietary potassium intake was normal, did not lead to functional renal potassium adaptation. To the contrary, the urinary excretion rate of potassium was even less in animals with elevated aldosterone levels than in animals with basal aldosterone levels. This finding is consistent with the observations in dogs by Berliner et al. (9), who found that, as long as dietary potassium intake was held constant, an increase in mineralocorticoids did not induce adaptation. We offer some possible explanations for this observation. It is likely that the high dose of aldosterone, inappropriate for a normal potassium diet, produces potassium depletion ( 9 , 32). As a consequence, kaliuresis after an acute infusion of $\mathrm{KCl}$ may be attenuated in that the infused $\mathrm{KCl}$ would be retained within body cells until potassium balance is restored $(17,18)$. It is also known that an increase in aldosterone shifts potassium into cells $(32-34,36)$. Accordingly, the infused $\mathrm{KCl}$ may move preferentially into the intracellular compartment.

The change in plasma potassium concentration after chronic aldosterone administration may also play a decisive role in modulating potassium excretion during an acute infusion of $\mathrm{KCl}$. Our results show that raising aldosterone levels from basal to high levels significantly lowers plasma potassium levels in animals on a control diet (from 3.99 to $2.90 \mathrm{meq} / \mathrm{liter}$, Table II). 
This might explain why potassium excretion failed to rise during the acute $\mathrm{KCl}$ infusion in the group with increased aldosterone levels on the control diet inasmuch as Young et al. (32) have also shown that urinary potassium excretion is relatively insensitive to alterations in plasma potassium when plasma potassium concentration is $<4 \mathrm{meq} /$ liter. Consistent with this is the observation that, after a rise in aldosterone in animals on the high potassium diet with a plasma potassium of $4.33 \mathrm{meq} / \mathrm{liter}$, urinary potassium excretion was significantly higher compared with animals having basal aldosterone levels who had plasma potassium levels of $4.43 \mathrm{meq} / \mathrm{liter}$.

The modifying role of plasma potassium in determining the renal effects of aldosterone is also demonstrated by the apparent dissociation of the functional and morphologic effects of aldosterone. Whereas high aldosterone induces significant amplification of the basolateral membrane of principal cells, it does not, as we now show, increase the ability to excrete an acute infusion of $\mathrm{KCl}$. As discussed above, the fall in plasma potassium levels after administration of the high aldosterone treatment inhibits the development of functional potassium adaptation.

Our results suggest that during periods of high potassium intake, an increase in aldosterone is required for the full development of functional renal potassium adaptation. This confirms the conclusions of Adam and Dawborn (6) and Thatcher and Radike (7) and others (1-16) that aldosterone is important in the development of potassium adaptation.

Our observation that increased dietary intake of potassium leads to a proliferation of the basolateral membrane of principal cells in the initial collecting tubule provides structural evidence that a high potassium diet induces adaptation. Hirsch et al. (12) have also shown that a high potassium diet enhances the surface density of the basolateral membrane of principal cells in the initial collecting tubule.

Our studies also demonstrate that there is a correlation between the length of the basolateral membrane of principal cells and the ability to excrete potassium in the urine (Fig. 5). However, two important exceptions are noted. First, as demonstrated in the present study, aldosterone increases membrane length in animals on a control diet but potassium excretion does not increase during infusion of $\mathrm{KCl}$ compared with animals having basal aldosterone levels. A second exception occurs during the renal response to acute infusion of $\mathrm{KCl}$ in adrenalectomized

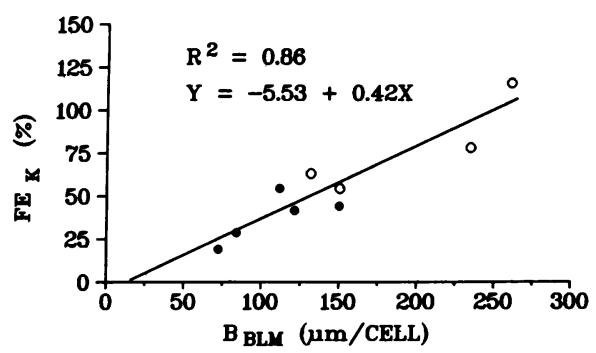

Figure 5. Relationship between fractional potassium excretion $\left(F E_{K}\right)$ and the length of the basolateral membrane of principal cells $\left(B_{B L M}\right)$ in the initial collecting tubule of rat. As discussed in the text there is a good correlation between the surface density of the basolateral membrane of principal cells and the ability to excrete an acute infusion of $\mathrm{KCl}$. The effects of an acute infusion of $\mathrm{KCl}$ on the ratio of membrane area to cell volume is not plotted. The values represented by the open circles are from the present study; values represented by the solid circles from Stanton et al. (26). Regression line calculated by least squares analysis. animals with basal aldosterone levels. Acute infusion of $\mathrm{KCl}$ does not increase membrane length, at least in the first $6 \mathrm{~h}$ (unpublished observations of J. Wade, M. Field, B. Stanton, and G. Giebisch). In this situation potassium excretion increased during infusion of $\mathrm{KCl}$ in the absence of membrane proliferation. However, this increase in excretion is less than that produced by a similar $\mathrm{KCl}$ infusion in animals chronically ingesting the high potassium diet $(2,35)$. This observation underscores the importance of the structural change in the collecting tubule in the development of potassium adaptation.

In summary, we have shown that an increase in dietary potassium intake, independent of a change in mineralocorticoid levels, elicits functional and structural renal potassium adaptation. However, an increase in both aldosterone and dietary potassium intake is required for the full development of functional renal potassium adaptation.

\section{Acknowledgments}

We thank Drs. David Young and Bruce Koeppen for helpful discussions and for a critical review of the manuscript.

This study was supported by the Hitchcock Foundation, Basic Research Support Grant funds from Dartmouth Medical School, and by National Institutes of Health grants DK- 34533 and DK-17433. B. Stanton is an Established Investigator of the American Heart Association.

\section{References}

1. Stanton, B. A., D. Biemesderfer, J. B. Wade, and G. Giebisch. 1981. Structural and functional study of rat distal nephron: Effects of potassium adaptation and depletion. Kidney Int. 19:36-48.

2. Stanton, B. A., and G. H. Giebisch. 1982. Potassium transpart by the renal distal tubule: effects of potassium loading. Am. J. Physiol. 243: F487-F493.

3. Fine, L. B., N. Yanagawa, R. G. Schultze, M. Tuck, and W. Trizna. 1979. Functional profile of the isolated uremic nephron: potassium adaptation in the rabbit cortical collecting tubule. J. Clin. Invest. 64:10331043.

4. Doucet, A., and A. I. Katz. 1980. Renal potassium adaptation: Na-K-ATPase activity along the nephron after chronic potassium loading. Am. J. Physiol. 238:F380-F386.

5. Miller, P. D., C. Waterhouse, R. Owens, and E. Cohen. 1975. The effect of potassium loading on the sodium excretion and plasma renin activity in Addisonian man. J. Clin. Invest. 56:346-353.

6. Adam, W. R., and J. K. Dawborn. 1968. Potassium tolerance in rats. Aust. J. Exp. Biol. 6:757-768.

7. Thatcher, T. S., and A. W. Radike. 1947. Tolerance to potassium intoxication in the albino rat. Am. J. Physiol. 151:138-146.

8. Adam, W. R., G. J. Goland, and R. M. Wellard. 1984. Renal potassium adaptation in the rat: Role of glucocorticoids and aldosterone. Am. J. Physiol. 246:F300-F308.

9. Berliner, R. W., T. J. Kennedy, and J. G. Hilton. 1950. Renal mechanisms for excretion of potassium. Am. J. Physiol. 162:348-367.

10. Rastegar, A., B. Biemesderfer, M. Kashgarian, and J. Hayslett. 1980. Changes in membrane surfaces of collecting duct cells in potassium adaptation. Kidney Int. 18:293-301.

11. Silva, P., R. S. Brown, and F. H. Epstein. 1977. Adaptation to potassium. Kidney Int. 11:466-475.

12. Hirsch, D., M. Kashgarian, E. L. Boulpaep, and J. P. Hayslett. 1984. Role of aldosterone in the mechanism of patassium adaptation in the initial collecting tubule. Kidney Int. 26:798-807.

13. Silva, P., J. P. Hayslett, and F. H. Epstein. 1973. The role of NaK-Activated adenosine triphosphatase in potassium adaptation: stimulation of enzyme activity by potassium loading. J. Clin. Invest. 52:22652271. 
14. Garg, L. C., and N. Narang. 1985. Renal adaptation to potassium in the adrenalectomized rabbit. Role of distal tubular sodium-potassium adenosine triphosphatase. J. Clin. Invest. 76:1065-1070.

15. Chekal, M., S. K. Mujais, and A. I. Katz. 1985. Time course and dose dependence of the changes in renal Na-K-ATPase during potassium adaptation. Clin. Res. 33:479A. (Abstr.)

16. Mujais, S. K., M. A. Chekal, W. J. Jones, J. P. Hayslett, and A. I. Katz. 1985. Modulation of renal sodium-potassium-adenosine triphosphatase by aldosterone: effect of high physiologic levels on enzyme activity in isolated rat and rabbit tubules. J. Clin. Invest. 76:170-176.

17. Stanton, B., and G. Giebisch. 1981. Mechanism of urinary potassium excretion. Miner. Electrolyte Metab. 5:100-120.

18. Wright, F. S. 1977. Sites and mechanisms of potassium transport along the renal tubule. Kidney Int. 11:415-432.

19. Mello-Aires, M., G. Giebisch, and G. Malnic. 1973. Kinetics of potassium transport across single distal tubules of rat kidney. J. Physiol. (Lond.). 232:47-70.

20. Schwartz, G. J., and M. B. Burg. 1978. Mineralocorticoid effects on cation transport by cortical collecting tubules in vitro. Am. J. Physiol. 235:F576-F585.

21. Wade, J. B., R. G. O'Neill, J. L. Pryor, and E. L. Boulpaep. 1979. Modulation of cell membrane area in renal cortical collecting tubules by corticosteroid hormones. J. Cell Biol. 81:439-445.

22. LeHir, M., B. Kaissling, and U. C. Dubach. 1982. Analysis of distal segments in the rabbit tubules after adaptation to altered $\mathrm{Na}$ and $\mathrm{K}$ intake. II Changes in Na,K-ATPase activity. Cell Tissue Res. 224 493-504.

23. Mujais, S. K., M. A. Chekal, W. J. Jones, J. P. Hayslett, and A. Katz. 1984. Regulation of renal Na-K-ATPase in the rat: role of the natural mineralo- and glucocorticoid hormones. J. Clin. Invest. 73:1319.

24. Kaissling, B., and M. LeHir. 1982. Distal tubular segments of the rabbit kidney after adaptation to altered $\mathrm{Na}$ and $\mathrm{K}$ intake. I. Structural changes. Cell Tissue Res. 224:469-492.

25. Stanton, B., G. Klein-Robbenhaar, J. Wade, G. Giebisch, and R. DeFronzo. 1985. Effects of adrenalectomy and chronic adrenal cor- ticosteroid replacement on potassium transport in rat kidney. J. Clin: Invest. 75:1317-1326.

26. Stanton, B. A., A. Janzen, J. Wade, R. DeFronzo, and G. Giebisch. 1985. Ultrastructure of rat initial collecting tubule: effect of adrenal corticosteroid treatment. J. Clin. Invest. 75:1327-1334.

27. Wright, F. S., N. Strieder, N. B. Fowler, and G. Giebisch. 1971. Potassium secretion by distal tubule after potassium adaptation. Am. J. Physiol. 221:437-448.

28. Schon, D. A., K. A. Backman, and J. P. Hayslett. 1981. Role of the medullary collecting duct in potassium excretion in potassium adapted animals. Kidney Int. 20:655-662, 1981.

29. Wingo, C. S., D. W. Seldin, J. P. Kokko, and H. R. Jacobson. 1982. Dietary modulation of active potassium secretion in the cortical collecting tubule of adrenalectomized rabbits. J. Clin. Invest. 70:579586.

30. Muto, S., S. C. Sansom, and G. Giebisch. 1986. Effects of high $\mathrm{K}$ diet on the transport properties of the isolated cortical collecting duct (CCD) of the adrenalectomized (ADX) rabbit. Kidney Int. 29:403A. (Abstr.)

31. Tomita, K., J. J. Pisano, and M. A. Knepper. 1985. Control of $\mathrm{Na}$ and $\mathrm{K}$ transport in the cortical collecting duct of rat: effects of bradykinin, vasopressin, and deoxycorticosterone. J. Clin. Invest. 76:132136.

32. Young, D. B., and A. W. Paulsen. 1983. Interelated effects of aldosterone and plasma potassium concentration on potassium excretion. Am. J. Physiol. 244:F28-F34.

33. Alexander, E. A., and N. G. Levinsky. 1968. An extrarenal mechanism of potassium adaptation. J. Clin. Invest. 47:740-748.

34. Bia, M. J., K. A. Tyler, and R. A. DeFronzo. 1982. Regulation of extrarenal potassium homeostasis by adrenal hormones in rats. Am. J. Physiol. 242:F641-F644.

35. Field, M. J., B. A. Stanton, and G. H. Giebisch. 1984. Differential acute effects of aldosterone, dexamethasone and hyperkalemia on distal tubular potassium secretion in the rat kidney. J. Clin. Invest. 74:17921802

36. Young, D. B., and T. E. Jackson. 1982. Effects of aldosterone on potassium distribution. Am. J. Physiol. 247:R526-R530. 